\title{
Ecological comparisons across geographical distributions: The thistle gall fly Urophora cardui (Diptera: Tephritidae) on two different Cirsium hosts
}

\author{
Mark FRENZEL ${ }^{1}, \mathrm{~S}_{\text {ABINE EBER }}{ }^{2}, \mathrm{STEFAN} \mathrm{KLOTZ}^{1}$ and Roland BRANDL ${ }^{1}$ \\ ${ }^{1}$ UFZ - Centre for Environmental Research Leipzig-Halle, Department of Community Ecology, Theodor-Lieser-Str. 4, \\ D-06120 Halle, Germany; e-mail: fre@oesa.ufz.de \\ ${ }^{2}$ School of Biology, E 47 Bute Building, St. Andrews University, St. Andrews, Fife, KY16 9TS, UK
}

Keywords. Biogeographic patterns, Tephritidae, Urophora cardui, Asteraceae, Cirsium arvense, C. setosum, gall former, parasitoids, Eurytomidae, Eurytoma, food web, phytophagous insects

\begin{abstract}
Populations of the specialist gall-forming fly, Urophora cardui (Diptera: Tephritidae), were studied at the western and eastern margins of its distribution. In western Europe $U$. cardui attacks the creeping thistle Cirsium arvense, whereas in eastern Europe, in the Ural mountains, it attacks Cirsium setosum, a taxon closely related to C. arvense. Gall densities are high in the Ural mountains and can be predicted by environmental variables. Compared to galls on C. arvense, those on C. setosum are on average larger. This indicates better performance of $U$. cardui on $C$. setosum in terms of cell numbers per gall. Despite the wide distribution of $U$. cardui, the dominant parasitoids are the same at the western and eastern ends of its distribution and the interactions between parasitoids and the host are similar. In general, we suggest that the synchronisation between the host plant species, the phytophage and the parasitoids is an important factor in the spatial ecology and evolution of this food web.
\end{abstract}

\section{INTRODUCTION}

In the Palaearctic many species have distributions covering thousands of kilometres from western Europe to Siberia. The emerging field of macroecology has shown that populations of species exhibit complex geographic patterns in terms of their densities and dynamics (Maurer, 1994). However, ecological studies comparing populations of a species throughout its distribution are rare, although such comparisons are essential to understand these spatial complexities. Phytophagous insects are prone to show complex geographic patterns due to their association with plant species, natural enemies and parasitoids (Thompson, 1994). Food web patterns may change as the associated species show varying distributional ranges. This can lead to host switches and subsequent speciation (Bush, 1992).

The tephritid fly Urophora cardui L. is a specialist stem gall former. It has been studied for several decades as a potential biocontrol agent of the creeping thistle Cirsium arvense (L.) Scopoli in Canada (Peschken \& Harris, 1975; Peschken et al., 1997). The palaearctic distribution of $U$. cardui ranges from western Europe to the Ural mountains and to Kazakhstan (Foote, 1984), and covers several climatic zones. Despite its huge distributional range $U$. cardui has a very restricted range of host plants. In the western and central parts of Europe it lives only on C. arvense. At the margins of the distribution of C. arvense, Urophora switches to two other host plants. In the eastern Mediterranean region it attacks the distantly related C. creticum (White \& Korneyev, 1989). From the Ukraine to the southern Urals and northern Kazakhstan $U$. cardui is reported from C. setosum (Willdenow) Iljin (Korneyev \& White, 1996). C. setosum is closely related to $C$. arvense as indicated by the clonal growth of the two taxa, a synapomorphic character within the genus Cirsium. The aim of the present study is to compare basic ecological characteristics like size and density of galls of $U$. cardui populations attacking $C$. setosum at the eastern margin of the distributional range with those of western European populations.

\section{MATERIAL AND METHODS}

\section{Biology of Urophora cardui}

All species of the subgenus Urophora s. str. feed on host plants belonging to the Cardueae, a tribe of the Asteraceae. While all other Urophora species induce galls in flower heads, $U$. cardui is the only species inducing stem galls. U. cardui has a univoltine life cycle. The adults appear in June and July, and females oviposit in the buds of stems and side shoots (Freese \& Zwölfer, 1996). The second instar larvae initiate a multilocular stem gall where each larva feeds in a separate cell. Thus, the number of cells indicates the original number of second instar larvae. Full-grown larvae overwinter in hardened stem galls and pupate during spring (Lalonde \& Shorthouse, 1985). Young larvae are mainly attacked by the parasitoids Eurytoma robusta Mayr and Eurytoma serratulae F. (Hymenoptera: Eurytomidae). In local populations these species may kill all of the larvae (Eber \& Brandl, 1994; Zwölfer, 1982).

\section{Population density estimates and habitat parameters}

Field work in western Europe (1987-1992) was carried out at C. arvense sites mainly in Upper Franconia, but also in the Rhine and the Danube valleys. The gall densities of $U$. cardui on C. arvense were recorded at 19 to 136 sites in Upper Franconia, 4 sites in the Rhine valley, and 8 sites in the Danube valley. The density at a given site was estimated by a time-sampling method, counting the number of $U$. cardui galls found in $10 \mathrm{~min}$ of random walking. This was always done by the same individuals. To calibrate the time-sampling data, the total number of galls in $28 \mathrm{C}$. arvense patches was determined (for details see Eber \& Brandl, 1994). The calibration allowed the mean 
number of galls per thistle stem at a site to be estimated. The number of host plants was counted at patches with less than 100 plants, and extrapolated for patches with more than 100 plants from counts of numbers per square meter. The abiotic habitat parameters like degree of moisture and exposure of host-plants to sunlight and wind were ranked from 1 ( $=$ low) to 4 ( $=$ high).

C. setosum was investigated in 1996 on the south-eastern side of the Ural mountains (Russia), near the city of Miass (the nature reserve of Jlmenskich). The climate is characterised by continental conditions with long winters and short periods of vegetative growth (Schubert et al., 1979). Compared to central Germany, temperature means in January are lower (Halle: $-0.4^{\circ} \mathrm{C}$; Utschaly, $100 \mathrm{~km}$ south-west of Miass: $-16.4^{\circ} \mathrm{C}$ ) and the frost-free period is much shorter (Halle: 202 days; Utschaly: 100 days). Annual precipitation is similar to central Germany (Halle: $502 \mathrm{~mm}$; Utschaly: $459 \mathrm{~mm}$ ). The sites are situated at an altitude of 400 to $600 \mathrm{~m}$. Habitats ranged from road sides to open places within forests, where C. setosum was always found in tall herb communities. In the Urals, the gall density of $U$. cardui was estimated at 20 randomly chosen sites, which were each searched for $10 \mathrm{~min}$ along transects, and the number of galls on each stem recorded. At small sites a complete census was done, whereas large sites were sampled using the time-sampling method. In western Europe, the degree of shading at thistle sites has proved to be important in determining the occurrence of U. cardui galls (Eber \& Brandl, 1994). Therefore the degree of shading at each $C$. setosum site except one $(n=19)$ was estimated on a scale from zero (not shaded) to three (completely shaded). Furthermore, we sampled the vegetation according to the Montpellier-Zürich-school (BraunBlanquet, 1964), using plots of about $10 \times 10 \mathrm{~m}$ Braun-Blanquet scores for coverage of the vegetation (rare; sparse; < 5; 5-25; 26-50; 51-75; 76-100\%) were recoded from one to seven and analysed by a principal components analysis on the covariance matrix (PCA; SYN-TAX, Podani, 1993). C. setosum was excluded from the PCA. Thus, we could use the cover of $C$. setosum as well as the scores of the sites derived from the PCA as independent variables to explain occurrence and density of $U$. cardui galls. In general, we used the cover of a plant as a measure of its abundance at a site.

\section{Gall samples}

Gall samples were collected in late summer when the galls were sclerotized and contained full-grown larvae. We collected between 36 and 177 stem galls from each of the $C$. arvense sites in western Europe and 100 galls in total from five $C$. setosum sites in the Urals. After measuring the gall diameter, the galls were dissected in the laboratory to estimate rates and causes of mortality of U. cardui.

\section{RESULTS}

\section{Occurrence, density of galls and habitat characteristics}

\section{Comparison of geographical sampling regions}

In the Urals, we found stem galls of $U$. cardui at 15 of 20 C. setosum sites. Gall densities at those 15 sites, estimated as the mean number of galls per plant, ranged from 0.01 to $0.51($ mean $=0.23)$. This corresponded to the gall densities found at $C$. arvense sites in the Rhine and the Danube valleys $(0.05-0.49$; mean $=0.20)$, but was about fourfold higher than in Upper Franconia (0.0002-0.67, mean $=0.050$ ). Performing an ANOVA with post-hoc contrasts showed differences in the mean densities between the Urals and Franconia $(p<0.001)$ and between

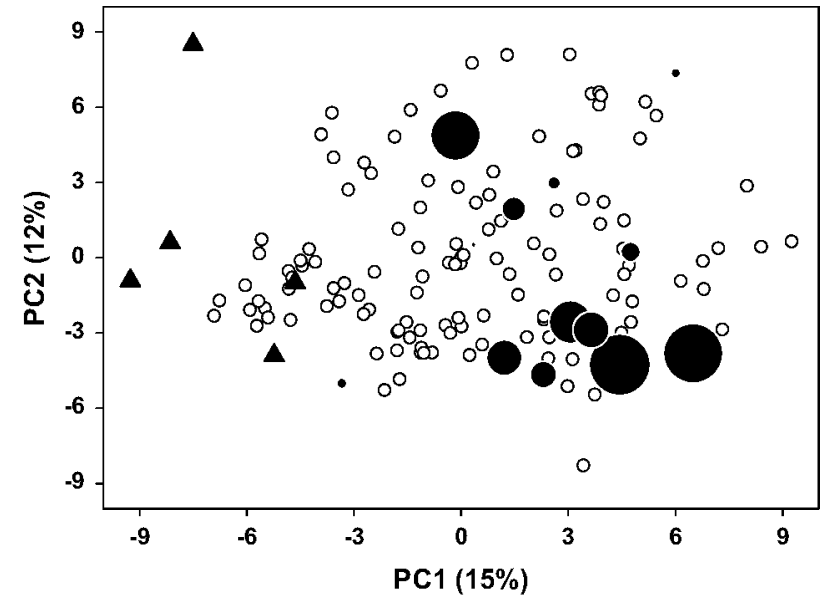

Fig. 1. Biplot of the first two axes, PC1 and PC2, of the principal components analysis (PCA). The PCA is based on the variance-covariance matrix of the abundance data of 205 plant species across $20 \mathrm{C}$. setosum sites. Symbols represent either plant species (open circles) or sites (triangles: sites without galls; filled circles: sites with galls; the diameter of circles is proportional to the density of galls).

Franconia and Rhine / Danube $(\mathrm{p}<0.001$; Tukeys honest significance difference test).

\section{Occurrence of galls (Urals)}

Analyzing the data from the Urals in more detail, we found no relation between the occurrence of galls and shading or abundance of the host plant (Spearman's rho: shading $\mathrm{p}=0.14$, abundance $\mathrm{p}=0.09$ ). More detailed habitat characteristics were included in our vegetation survey, which included 206 plant species. The PCA using the abundance index of all the plant species, except C. setosum, accounted for 15 and $12 \%$ of the total variance of the first two axes (Fig. 1). Occupied and nonoccupied sites showed significant differences along PC1 (Spearman's rho: $p<0.001$ ), but not along PC2 (Spearman's rho: $p>0.2)$. Note that shading is correlated with $\mathrm{PC} 1(\mathrm{r}=0.59, \mathrm{p}=0.007)$, indicating that $\mathrm{PC} 1$ includes a gradient from sunny to shady sites. Furthermore, a ranking of scores of $\mathrm{PC} 1$ showed that the associated plant species represent annuals and therophytes at low, and perennials at high scores. Thus low scores may stand for vegetation typical of disturbed habitats, whereas high scores may indicate undisturbed habitats. In total, the perennials make up $78 \%$ of the species.

\section{Density of galls (Urals) and habitat characteristics}

To find predictors for gall density on C. setosum, we performed a multiple regression with shading, host abundance, squared host abundance, PC1 and PC2 as independent variables (Table 1). We included the squared term of host abundance, as the univariate scatter diagrams suggested a humped-shaped relationship between host abundance and gall density. Overall, the model explained $74 \%$ of the variability in gall density between sites (Fig. 2 ). If the variables extracted from the vegetation surveys (PC1, PC2) are excluded from the multiple regression, still $59 \%$ of the variability was explained by shading and 
TABLE 1. Results of a backward stepwise regression of the density of $U$. cardui galls with habitat parameters of $C$. setosum sites and PCA axes (PC1, PC2). $\mathrm{R}^{2}$ - variation explained by the model, (corr) corrected by degrees of freedom; d.f. - degrees of freedom of the model (of the residuals); $\mathrm{p}$ (F-test), $\mathrm{p}$ (beta) - level of significance of the F-test, of beta-weights; beta - regression coefficients.

\begin{tabular}{|c|c|c|c|c|c|c|c|}
\hline Step number & Variable excluded & $\mathrm{R}^{2}$ (corr.) & d.f. & $\mathrm{p}$ (F-test) & Variable in equation & beta & $\mathrm{p}$ (beta) \\
\hline \multirow[t]{5}{*}{$\overline{0}$} & & $0.74(0.64)$ & $5(13)$ & 0.002 & abundance & 1.27 & 0.047 \\
\hline & & & & & $(\text { abundance) })^{2}$ & -1.22 & 0.058 \\
\hline & & & & & shading & 0.52 & 0.013 \\
\hline & & & & & $\mathrm{PC} 1$ & 0.07 & 0.750 \\
\hline & & & & & $\mathrm{PC} 2$ & -0.39 & 0.020 \\
\hline \multirow[t]{4}{*}{1} & PC1 & $0.74(0.66)$ & $4(14)$ & 0.001 & abundance & 1.38 & 0.012 \\
\hline & & & & & (abundance) $^{2}$ & -1.33 & 0.013 \\
\hline & & & & & shading & 0.56 & 0.002 \\
\hline & & & & & $\mathrm{PC} 2$ & -0.40 & 0.015 \\
\hline \multirow[t]{3}{*}{2} & $\mathrm{PC} 2$ & $0.59(0.51)$ & $3(15)$ & 0.003 & abundance & 1.61 & 0.012 \\
\hline & & & & & (abundance) $^{2}$ & -1.50 & 0.019 \\
\hline & & & & & shading & 0.48 & 0.013 \\
\hline
\end{tabular}

host abundance (see Table 1, step 2). A similar attempt to use data from Upper Franconia to predict gall densities of $U$. cardui, which included a wide range of environmental variables (light, moisture, wind, altitude, host plant density, patch size), yielded only marginally significant multivariate models that explained little more than $10 \%$ of the total variance (Eber \& Brandl, 1994).

The negative regression coefficient of the relationship between density of galls and squared host plant abundance (Table 1) confirms statistically the hump-shaped relationship. To determine the qualities of single plant species we related indicator values for their requirements for nitrogen (Ellenberg, 1979; computerized lists of indicator values by Frank \& Klotz, 1990) to their PC2 scores. This indicated that $\mathrm{PC} 2$ represents a plant species requirement for nitrogen: Low $\mathrm{PC} 2$ values indicating plant spe-

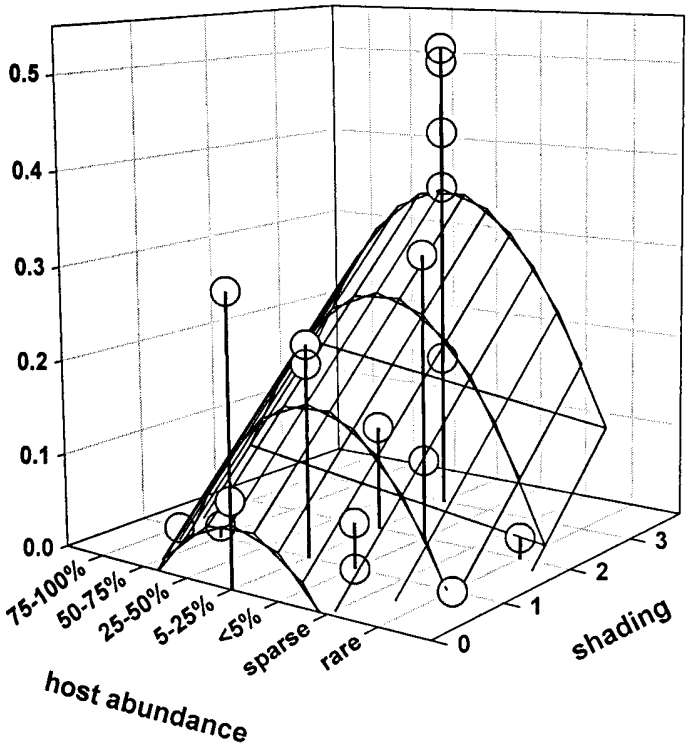

Fig. 2. Plot of gall density versus shading and cover/abundance of $C$. setosum. The three dimensional mesh plot shows the predicted values from the multiple regression model. This model explained $74 \%$ of the variance and included the site scores of PC2 (see Fig. 1). For the purpose of this plot we set the beginning of the $\mathrm{PC} 2$ score to zero.
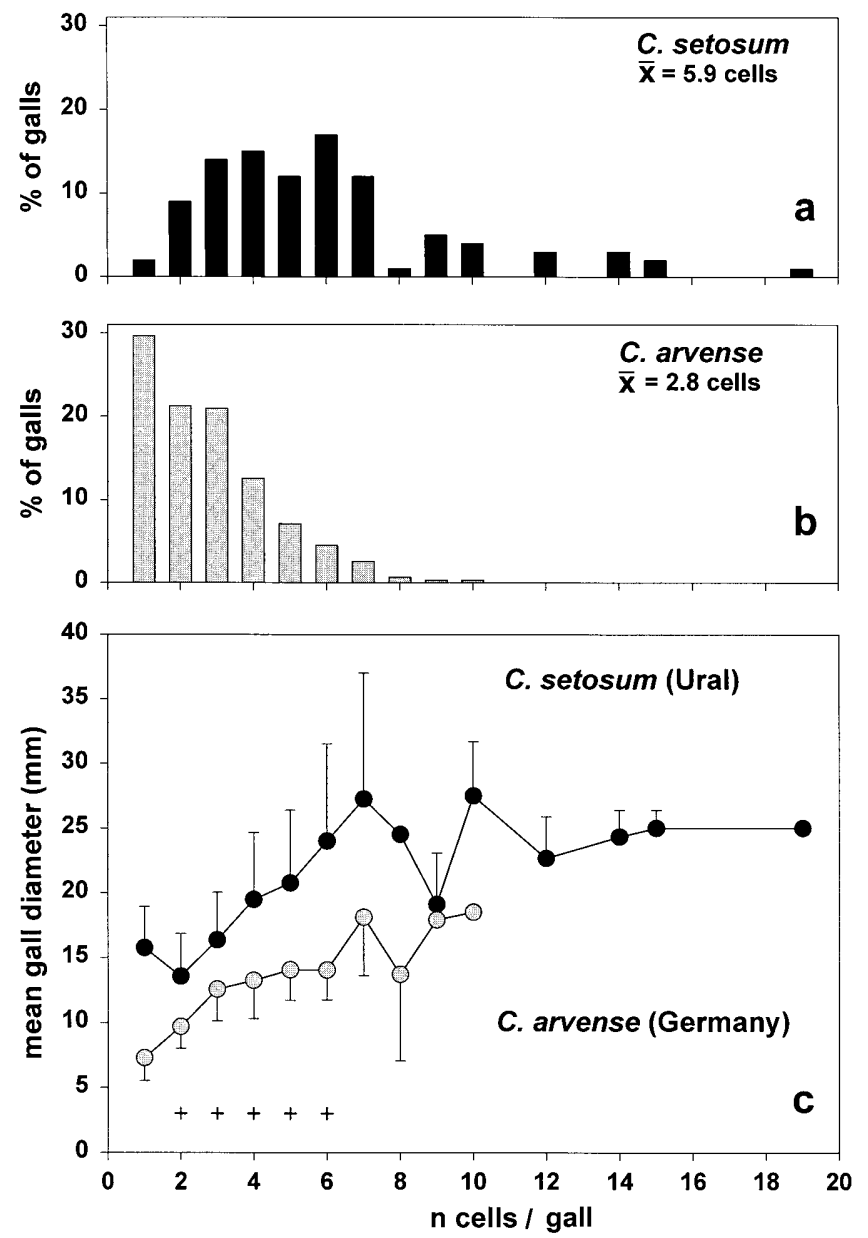

Fig. 3. Frequency distribution of cell numbers of galls from (a) C. setosum and (b) C. arvense. (western Europe: pooled data from Upper Franconia, Rhine and Danube valley); the two distributions $(\mathrm{a}, \mathrm{b})$ are significantly different $\left(\mathrm{chi}^{2}=113\right.$, $\mathrm{df}=13, \mathrm{p}<0.005$ ). (c) Number of cells versus gall size on C. setosum (Urals; $\mathrm{n}=100$ dissected galls) and $C$. arvense (western Europe; $n=310$ dissected galls). Error bars give the standard deviation, + indicates significant t-tests after Bonferroni correction). 


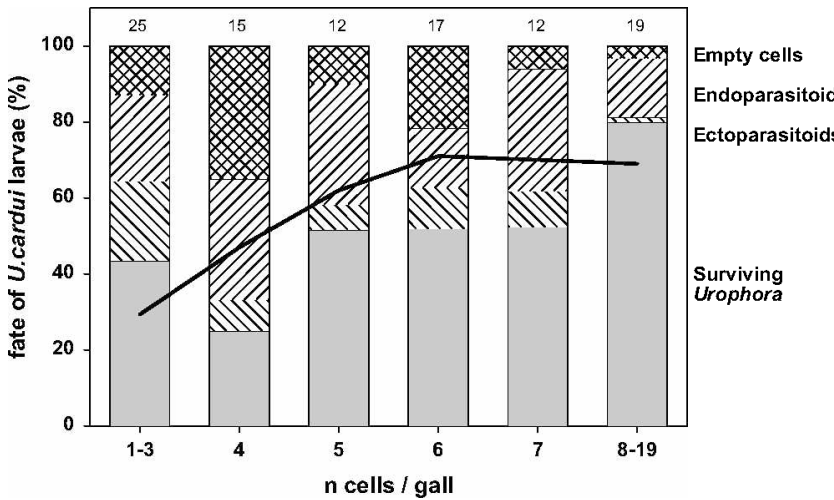

Fig. 4. Survival and mortality rates of $U$. cardui larvae on $C$. setosum related to the number of cells per gall. Mortality was due to ectoparasitoids, endoparasitoids and unknown factors operating during gall development. These unknown factors cause empty cells within a gall. The mortality factors decrease with gall size $\left(\mathrm{chi}^{2}=125 ; \mathrm{df}=15, \mathrm{p}<0.005\right)$. For comparison we plot a line for the proportion of $U$. cardui larvae that survived on C. arvense in western Europe (Belfort area; Zwölfer \& Arnold-Rinehart, 1994). Numbers above columns indicate sample size.

cies from nitrogen-rich sites and high PC2 values the reverse.

\section{Gall size}

On average, galls of $U$. cardui on C. setosum were about double the size of those on $C$. arvense (Urals: mean $=21.1 \mathrm{~mm}$; western Europe: mean $=10.8 \mathrm{~mm}$; see also data by Freese \& Zwölfer, 1996) and contained at least twice the number of cells (Fig. 3a, b). Furthermore, for a given number of cells the galls of $U$. cardui on C. setosum were larger than those on C. arvense (Fig. 3c).

\section{Rates of mortality}

The Urophora galls $(\mathbf{n}=100)$ from $C$. setosum contained 581 cells. We obtained 402 Urophora larvae (350 living, 52 dead for unknown reasons), 45 ecto- and 134 endoparasitoid larvae. As each parasitoid needs a single Urophora larva for development, 179 larvae (31\%) were killed by parasitoids. The two parasitoid species in the Urals gall samples were the same as in western Europe: the ectoparasitoid Eurytoma robusta Mayr and the endoparasitoid E. serratulae $\mathrm{F}$. The rates of parasitism varied considerably between the five $C$. setosum sites sampled (Table 2). Compared to the data from Upper Franconia
(Eber \& Brand1, 1994), where the parasitism rates were similar to the Urals, endoparasitoids contributed much more to the total parasitism rate than ectoparasitoids (Table 2). However, in other areas of Europe, endoparasitoids may be as important as ectoparasitoids, especially where galls are large (Zwölfer \& Arnold-Rinehart, 1994).

A plot of the number of cells per gall versus different mortality factors shows that probability of survival of larvae of $U$. cardui in C. setosum galls increases with the number of cells per gall (Fig. 4). The number of empty cells, caused by deficiencies in the process of gall formation or parasitoid attack, decreased with increasing gall size ( $=$ increasing number of cells). Comparing these results with data extracted from Zwölfer \& ArnoldRinehart (1994; Fig. 4.) indicates that parasitism rates of galls on C. setosum in the Urals and on C. arvense in western Europe are also correlated with cell number.

\section{DISCUSSION}

The comparison of western European populations of $U$. cardui with populations sampled in the Urals yielded five main results:

At the eastern edge of its distribution, where the original host $C$. arvense becomes rare, $U$. cardui attacks the closely related $C$. setosum.

$U$. cardui was most likely to be found at shaded undisturbed sites where its host plant is abundant.

In contrast to C. arvense in Upper Franconia, gall densities on C. setosum in the Ural mountains are high and can be predicted by environmental variables, i.e. shading of the habitat, abundance of host plants and nitrogen status of the site.

Compared to $C$. arvense, gall diameter and number of cells per gall are on average greater on C. setosum, which indicates better performance of $U$. cardui on C. setosum.

Despite the large distributional range of $U$. cardui, it has some common parasitoids at the western and the eastern edges of its distribution. The interaction between parasitoids and $U$. cardui larvae in the Urals is the same as in western Europe. However, endoparasitoids are more important in the Urals because of the larger galls on C. setosum.

\section{Host shifts, gall density and population structure of U. cardui}

Although highly specialised phytophagous insects are often associated with a single host plant, host shifts are

TABLE 2. Cells per gall and parasitism rates of $U$. cardui in western Europe and the Ural mountains. Parasitism rates (\%) include ecto- and endoparasitoids.

\begin{tabular}{lcccccc}
\hline Locality & year & number of sites & dissected galls & cells/gall & parasitism rate & proportion of ectoparasitism \\
\hline Franconia & 1987 & 47 & 1090 & 3.7 & 27.7 & 93.2 \\
Franconia & 1991 & 50 & 800 & 3.7 & 77.1 & 96.0 \\
Ural & 1996 & 5 & 100 & & & 1.5 \\
$\# 1$ & & & 25 & 5.4 & 34.6 & 7.1 \\
$\# 2$ & & 21 & 4.7 & 43.4 & 36.6 \\
$\# 3$ & & 20 & 4.1 & 74.4 & 3.1 \\
$\# 4$ & & & 14 & 10.7 & 20.0 & 1.4 \\
m5 & & & & 5.9 & 30.4 & 25.4 \\
\hline
\end{tabular}


known to occur on geographical scales (Zwölfer \& Romstöck-Völkl, 1991). These host shifts are likely if the original host at the margins of its distribution is replaced in a spatial contact zone by a related host species with a similar ecology. This can lead to the formation of biotypes or host races of phytophages and is thought to be a major mechanism of speciation in phytophagous insects (Bush, 1992).

The Ural mountains are an east-west barrier to dispersal, and separate the floras of Europe and Asia. They are the north-eastern border of the distribution of C. arvense (Meusel \& Jäger, 1992). South of the Urals, $C$. arvense extends far to the east. There is an overlap in the range of $C$. arvense and $C$. setosum indicating that these two closely related taxa are sister taxa formed by an allopatric event. On the other hand, the distributional data on $U$. cardui provided by Foote (1984) indicate that the north-eastern margin of its distribution are the Ural mountains. Thus it is not surprising that $U$. cardui switches to $C$. setosum in the Ural mountains. This kind of resource tracking also occurs at the southern margin of the distribution of $C$. arvense, where $U$. cardui attacks C. creticum, a species occurring along lake shores of the eastern Mediterranean. In contrast to the close relationship between $C$. arvense and $C$. setosum, allozyme studies on $C$. creticum show that it is only distantly related to $C$. arvense (Steinert, 1992). Although $C$. arvense occurs in the Mediterranean area, its abundance is rather low there and $U$. cardui switches to a host which is common in wet sites.

$U$. cardui prefers wet and shaded sites (Eber \& Brandl 1994; Figs 1,2) and reaches the highest gall densities in Europe in riverine forests. Zwölfer (1982) concluded that originally $C$. arvense and $U$. cardui have been species of riverine forests and that these forests were the main pathways for $U$. cardui to invade Europe in the post-pleistocene (but see Eber \& Brandl, 1997). Furthermore, Freese \& Zwölfer (1996) noted that gall formation in a population at high altitudes is limited by low temperature. Thus, the high densities of $U$. cardui at the continental sites of $C$. setosum were of some surprise.

Different climatic zones at the western and eastern margins of the distribution may explain the differences in gall density across the area of distribution, as the climate determines the time span for synchronisation between host plant and insect. For example, temperatures above $10^{\circ} \mathrm{C}$ provide suitable conditions for the growth of vegetation. In western Europe this occurs on 172 days each year (Halle, central Germany), but only on 120 days in the Urals (Utschaly) (Schubert et al., 1979). Thus, the time for plant growth is shorter in the Urals, leading to a more synchronised development of host plants. Consequently, a higher proportion of plants will be suitable for oviposition, increasing the chance of the flies finding suitable hosts. Especially for a species that shows timelimited oviposition, like U. cardui (Freese \& Zwölfer, 1996), this synchronisation hypothesis predicts higher infestation rates in the Urals. As the time of suitable conditions for the growth of vegetation decreases with lati- tude, increasing infestations rates with latitude are to be expected. The geographic pattern in the infestation rate by the tephritid fruit fly Tephritis conura supports this idea: Romstöck \& Arnold (1987) showed an increase in infestation rates with increasing latitude in two different host plants, Cirsium palustre and Cirsium heterophyllum.

The difference in the predictive power of parameters influencing gall densities in Upper Franconia and the Ural mountains may indicate different regional population structures in the two areas. The populations of $U$. cardui in Upper Franconia form a dynamic metapopulation with frequent local extinctions and colonisations (Eber \& Brandl, 1994, 1997). This is indicated by the prominent importance of patch size as a predictor of the occurrence of $U$. cardui in Upper Franconia, whereas local gall densities were variable and therefore appeared erratic. This is in marked contrast with what happens at the eastern margin of the distribution, which suggests that extinction and colonisation is less dynamic there compared to metapopulations in the agricultural areas of Upper Franconia. This idea is supported by the observation that the occurrence of galls on $C$. setosum is correlated with the parameter PC1: that is the occurrence of galls is associated with scores indicating undisturbed and thus less dynamic habitats (Fig. 1). But PC1 does not explain the density of galls, which is influenced by PC2 (Table 1), which characterises the nitrogen status of a site.

\section{Parasitoids and gall size}

Parasitoids of $U$. cardui are at least as intimately connected to the fly as the fly is to its host plant. The close association is demonstrated by the identical set of parasitoid species throughout the distributional range of $U$. cardui. The close association of Eurytoma with Urophora throughout the palaearctic region was noted by Zwölfer \& Arnold-Rinehart (1993). Two other ectoparasitoid species, which attack $U$. cardui at rates below $1 \%$ in western Europe (Torymus chloromerus, Pteromalus elevatus) were not recorded in the Urals, but this is likely to be a consequence of small sample size. The climatic conditions in the Urals, which result in a stronger synchronisation of plant development compared to western Europe, should increase parasitism rates in the same way as infestation rates caused by the phytophage (see above). However, the parasitism rates were similar to those in western Europe.

The size of galls has two important consequences. (1) Gall size, parasitism rates and competition between endoparasitoids and ectoparasitoids are associated. The ectoparasitism rates of host larvae show a negative correlation with gall growth (Schlumprecht, 1990; Zwölfer \& Arnold-Rinehart, 1994). That is, the females of the ectoparasitoid are unable to attack larvae in large galls because they are beyond the reach of the parasitoids ovipositor. In contrast, the endoparasitoid attacks larvae at an early stage in their development when the gall is still small and the development of the endoparasitoid is dependent on the continued life of its host larva. Because the endoparasitoid attacks the host first it may also be killed by the ectoparasitoid. On balance, the increased 
gall size on C. setosum allows Urophora larvae as well as endoparasitoids to escape the risk of attack by the ectoparasitoid. (2) Gall size also directly affects the fitness of the larvae. Freese \& Zwölfer (1996) report that the survival of third-instar larvae to pupation is positively affected by gall size. Furthermore, mean larval weight, adult weight and fecundity is positively related to gall size (Freese \& Zwölfer, 1996). Thus, gall size is a crucial fitness parameter for $U$. cardui on $C$. arvense.

We suggest that the findings of Freese \& Zwölfer (1996) also apply to U. cardui on the closely related host plant C. setosum. Our results pose another question: Why do the galls on C. setosum have more cells, and why are those with a given number of cells larger than on $C$. arvense? Clutch sizes of $U$. cardui on $C$. arvense are much larger than there are cells in the galls (Freese \& Zwölfer, 1996), which indicates a high mortality in the egg or young larval stages. From our findings we suggest two non-exclusive hypotheses to explain the increased cell number of galls on C. setosum. (1) Females of $U$. cardui in the Urals lay more eggs than females in western Europe. (2) Mortality of eggs or small larvae is lower in the Urals than in western Europe. But why should the galls be larger? The difference in gall size may be due to inherent structural differences between the two host species, which have not been explored yet. Alternatively, gall growth and gall size are influenced by the vigour of the host plant, which is known to be influenced by nutrient status, water supply and other environmental factors (Freese \& Zwölfer, 1996). Gange \& Nice (1997) showed that the absence of mycorrhizal fungi promoted gall growth on $C$. arvense, but this varies between clones of the host plant (see also Horner \& Abrahamson, 1992). However, there is no evidence that the nitrogen supply to the host affects gall size. In conclusion, the increased gall size on C. setosum may be either an effect of the environment or of the evolutionary history. The latter point suggests two interesting hypotheses for further research. (1) The increased gall size indicates that C. setosum is not well adapted to attack by $U$. cardui, which would account for the low mortality rates of eggs and the large gall size as well. (2) The increased gall size is an adaptive strategy of $U$. cardui which enables it to escape from ectoparasitoids.

\section{CONCLUSION}

Although our results from the Urals are based on one year only, they demonstrate interesting similarities, but also differences in the ecology of $U$. cardui in western and eastern Europe. Most of the explanations for the differences are speculative, and a more detailed observational and experimental comparison may help us to understand the complexities of the spatial ecology of this phytophagous insect. The new political situation may facilitate collaboration between Russian and European scientists aimed at understanding the geographic variation in ecological patterns throughout the distribution of a species.
ACKNOWLEDGEMENTS. We are grateful to H. Zwölfer and an anonymous reviewer for helpful comments on the manuscript.

\section{REFERENCES}

Braun-Blanquet J. 1964: Pflanzensoziologie. Springer, Wien, $865 \mathrm{pp}$.

Buss G.L. 1992: Host race formation and sympatric speciation in Rhagoletis fruit flies (Diptera: Tephritidae). Psyche 99: 335-357.

EBER S. \& BRANDL R. 1994: Ecological and genetic spatial patterns of Urophora cardui (Diptera: Tephritidae) as evidence for population structure and biogeographical processes. $J$. Anim. Ecol. 63: 187-199.

EBER S. \& BRANDL R. 1997: Genetic differentitation of the tephritid fly Urophora cardui in Europe as evidence for its biogeographical history. Mol. Ecol. 6: 651-660.

Ellenberg H. 1979: Zeigerwerte der Gefäßpflanzen Mitteleuropas. Scripta Geobotanica. Vol. 9. Goltze, Göttingen, 122 pp.

Foote R.H. 1984: Family Tephritidae (Trypetidae). Catalogue of Palearctic Diptera. Elsevier Science \& Akademiai Kiado, Budapest, pp. 66-149.

FRANKK D. \& Klotz S. 1990: Biologisch-ökologische Daten zur Flora in der DDR. Martin-Luther-Univ. Halle-Wittenberg, Halle (Saale), $167 \mathrm{pp}$.

Freese G. \& Zwölfer H. 1996: The problem of optimal clutch size in a tritrophic system: The oviposition strategy of the thistle gallfly Urophora cardui (Diptera, Tephritidae). Oecologia 108: 293-302.

Gange A.C. \& Nice H.E. 1997: Performance of the thistle gall fly, Urophora cardui, in relation to host plant, nitrogen and mycorrhizal colonisation. New Phytol. 137: 335-343.

Horner J.D. \& ABRAHAMSON W.G. 1992: Influence of plant genotype and environment on oviposition preference and offspring survival in gallmaking herbivores. Oecologia 90: 323-332.

KorneYeV V.A. \& White I.M. 1996: Fruit flies of the genus Urophora R.-D. (Diptera, Tephritidae) of eastern Palaearctics. II. Review of species of the subgenus Urophora s. str. Communication 3. Entomol. Rev. 76: 499-513.

LALONDE R.G. \& Shorthouse J.D. 1985: Growth and development of larvae and galls of Urophora cardui (Diptera, Tephritidae). Oecologia 65: 161-165.

Maurer B.A. 1994: Geographical Population Analysis: Tools for the Analysis of Biodiversity. Methods in Ecology. Blackwell, Oxford, 130 pp.

MEUSEL H. \& JÄGER E. 1992: Vergleichende Chorologie der zentraleuropäischen Flora - Karten, Literatur, Register. Vol 3. Gustav Fischer, Jena, pp. 422-688.

Peschren D.P. \& Harris P. 1975: Host specifity and biology of Urophora cardui (Diptera: Tephritidae). A biocontrol agent for Canada thistle (Cirsium arvense). Can. Entomol. 107: $1101-1110$.

Peschken D.P., Derby J.L. \& Spann D.T. 1997: Establishment of Urophora cardui (Diptera: Tephritidae) on Canada thistle, Cirsium arvense (Asteraceae), and colony development in relation to habitat and parasitoids in Canada. In Dettner K., Bauer G. \& Völkl W. (eds): Vertical Food Web Interactions. Springer, Berlin, pp. 53-66.

Podant J. 1993: SYN-TAX-pc 5.0. Scientia Publishing, Budapest, $104 \mathrm{pp}$.

ROMSTÖCK M. \& ARNOLD H. 1987: Populationsökologie und Wirtswahl bei Tephritis conura Loew Biotypen (Dipt.: Tephritidae). Zool. Anz. 219: 83-102.

SCHLUMPRECHT H. 1990: Untersuchungen zur Populationsökologie des Phytophagen-Parasitoid-Systems von Urophora 
cardui L. (Diptera: Tephritidae). PhD. Thesis, University of Bayreuth, Germany, 190 pp.

Schubert R., JäGER E.J. \& MaHN E.-G. 1979: Vergleichende geobotanische Untersuchungen in der Baschkirischen ASSR. Hercynia 16: 206-263.

STEINERT I. 1992: Populationsbiologische Untersuchungen an Arten der Gattung Cirsium Miller. PhD. Thesis, Universität Bayreuth, Germany, 175 pp.

Thompson J.N. 1994: The Coevolutionary Process. University of Chicago Press, Chicago, 376 pp.

White I.M. \& KorneYeV V.A. 1989: A revision of the western Palaearctic species of Urophora Robineau-Desvoidy (Diptera: Tephritidae). Syst. Entomol. 14: 327-374.

ZwÖLFER H. 1982: Das Verbreitungsareal der Bohrfliege Urophora cardui L. (Diptera: Tephritidae) als Hinweis auf die ursprünglichen Habitate der Ackerdistel [Cirsium arvense (L.) Scop.]. Verh. Dtsch. Zool. Ges. 75: 298.
ZWÖLFER H. \& ARNOLd-RineharT J. 1993: The evolution of interactions and diversity in insect-plant systems: The Urophora-Eurytoma food web in galls on palearctic Cardueae. In Schulze E.D. \& Mooney H.A. (eds): Ecological Studies. Springer, Heidelberg, pp. 211-229.

ZWÖLFER H. \& ARNOLD-RINeHART J. 1994: Parasitoids as a driving force in the evolution of the gall size of Urophora on Cardueae hosts. In Williams M.A.J. (ed.): Plant Galls. Clarendon, Oxford, pp. 245-257.

ZWÖLFER H. \& ROMSTÖCK-VÖLKL M. 1991: Biotypes and the evolution of niches in phytophagous insects on Cardueae hosts. In Price P.W. (ed.): Plant-Animal Interactions: Evolutionary Ecology in Tropical and Temperate Regions. John Wiley, New York, pp. 487-507.

Received July 22, 1999; accepted October 11, 1999 